\title{
Autoconocimiento: una idea tensa
}

\author{
EFRAÍN LAZOS \\ Instituto de Investigaciones Filosóficas \\ Universidad Nacional Autónoma de México \\ eflazos@unam.mx
}

\begin{abstract}
Resumen: En este ensayo se explora la idea de autoconocimiento y algunas otras asociadas a ella (autoconciencia, autoatribución, autoridad personal). La conjetura central es que la de autoconocimiento es una idea tensa en cuanto que contiene dos exigencias en competencia: el desapego y el involucramiento. La primera pide vernos a nosotros mismos imparcialmente, o al menos como nos vería cualquier otra persona; la segunda, vernos como nunca podría hacerlo cualquier otro. Apelando a modelos y autores de la tradición filosófica moderna y contemporánea, se muestran distintas maneras en las que, al favorecer cualquiera de estas demandas sobre la otra, resulta distorsionado algún aspecto de la subjetividad humana. En las secciones finales, y siguiendo una idea de R. Moran (2001), se sugiere que es posible hacer justicia a ambas demandas si se adopta una perspectiva deliberativa de la autoridad que tienen las personas sobre su propia vida mental.
\end{abstract}

Palabras clave: autoconciencia, autoatribución, transparencia, autoridad

\begin{abstract}
This essay explores self-knowledge and some related ideas (selfconsciousness, self-attribution, personal authority). Its main conjecture is that self-knowledge is a tense idea, in so far as it contains two competing demands, namely detachment and involvement. The former asks that we see ourselves impartially, or at least like any other person might see us. The latter requires that we see ourselves like no one else could. Having in view models and authors from the modern and contemporary philosophical traditions, the essay shows various ways in which, when one demand is favored over the other, some aspect of human subjectivity is distorted. In the final parts of the essay, and following an idea of R. Moran (2001), the author suggests that it is possible to do justice to both demands if we adopt a deliberative perspective on the authority that persons have over their own inner lives.
\end{abstract}

Key words: self-consciousness, self-attribution, transparency, authority

1. La idea de autoconocimiento es vieja, tal vez incluso más que la filosofía tal y como la hemos conocido. Hay alguna idea de autoconocimiento en las tradiciones arcaicas, así como en los textos fuente de las diversas ortodoxias religiosas presentes; y la hay también para esa forma de vida, idealmente gobernada por la educación y la ciencia, que llamamos nuestra. Es una tarea difícil, no obstante, decir en qué consiste tal idea, como lo es igualmente presentar ejemplos cabales de autoconocimiento.

Diánoia, volumen LIII, número 61 (noviembre 2008): pp. 169-188. 
Creo que la mayoría de las personas aceptaría la noción de que así como cada cual sabe un cúmulo de cosas, desde las más triviales y circunstanciales, hasta las más dramáticas e importantes, acerca de uno mismo, así también cada cual ignora muchas cosas sobre sí mismo. Una sugerencia que surge aquí es que el autoconocimiento puede verse como el conocimiento de hechos acerca de nosotros mismos; e.g., nuestro ADN; nuestros pesos y medidas; nuestras creencias, emociones y deseos; nuestras actitudes morales y políticas; nuestros estados civiles y financieros, etc. En este sentido, la idea de autoconocimiento seguiría la lógica de concepto de saber como una especie de creencia: aquel que usamos para caracterizar un logro de una persona o de una comunidad, por lo general usando diversas fuentes de evidencia para creencias específicas. Como sucede con cualquier creencia, incluso las creencias más arraigadas sobre uno mismo pueden resultar falsas; pero, en contraste, sería sumamente difícil, si no es que de plano imposible, tener sólo creencias falsas sobre uno mismo. Los datos de mi acta de nacimiento, por ejemplo, pueden ser todos falsos; quienes hasta ahora he tomado como mis padres pueden no ser mis padres biológicos, y mi propia historia personal puede resultar ser radicalmente diferente de lo que hasta ahora he creído. Llegar a hacer descubrimientos como los anteriores puede ser muy doloroso, y hasta desastroso para la integridad psicológica de quien los hace. ${ }^{1}$ No obstante, siempre hay una cantidad limitada de creencias falsas que una persona puede tener sobre sí misma. Al menos psicológicamente, diríamos que una persona no puede tener sólo creencias falsas sobre sí misma, a riesgo de la alienación.

Las diferencias entre las maneras en las que logramos tener acceso a los diversos tipos de hechos sobre nosotros mismos pueden resultar relevantes de caso en caso. Seguramente saber que mis pesos y medidas son tales y cuales requiere un conjunto de recursos y evidencias distinto del que se requiere para saber que tengo tales y tales convicciones políticas, o que poseo tal y cual herencia genética; y estos recursos serán, acaso, distintos, a su vez, cuando se trata de mis deseos, miedos y cosas así. En todos estos casos parece perfectamente posible cuestionar el alcance y la calidad del autoconocimiento que le atribuimos a una persona, o que una persona se atribuye a sí misma. Aun en la situación más radical, no obstante, tales cuestionamientos constituirían una forma de sarcasmo dirigido ya sea a otros, ya sea a uno mismo; pero no

\footnotetext{
${ }^{1}$ Como por desgracia lo demuestran numerosos casos de infantes desaparecidos durante las dictaduras y "dictablandas" latinoamericanas.
}

Diánoia, vol. LIII, no. 61 (noviembre 2008). 
parecen plantear ningún reto escéptico en contra de la idea misma de autoconocimiento. La idea, en otros términos, de que cualquier creencia sobre uno mismo puede resultar falsa no tiene por qué conducir a la idea, harto distinta, de que todas ellas pueden serlo. El autoconocimiento, como todo saber, acaso, descansa sobre un lecho movedizo de certezas.

Consideremos ahora una pregunta que, creo, surge naturalmente después de las reflexiones anteriores: ¿es el autoconocimiento saber de hechos acerca de mí mismo? Hay una importante condición: que uno pueda expresar el saber en cuestión usando el término "yo". Esto se traduce en la idea de que no cualquier creencia acerca de uno mismo puede valer como autoconocimiento. Edipo en Colona tenía una creencia acerca de sí mismo cuando creía que el asesino de Layo debía ser ejecutado; pero ésa no era la creencia de que él, Edipo, debía ser ejecutado. En general, yo puedo saber un cúmulo de cosas acerca de mí mismo y no saber que todo eso me concierne a mí. De modo que para que una creencia sobre mí mismo pueda contar como autoconocimiento, tengo que percatarme de que la persona de la que, en $\mathrm{mi}$ creencia, afirmo que ha realizado tales y cuales acciones, o que tiene tales y cuales emociones, creencias, características físicas u otras cosas, soy yo mismo y no otra. Digamos que ésta es la condición de autoconciencia para las creencias acerca de uno mismo que pueden aspirar a contar como autoconocimiento.

Preguntemos, entonces, ¿es el autoconocimiento saber autoconcientemente hechos acerca de uno mismo? ¿Acaso la recomendación délfica "Conócete a ti mismo" demanda de Sócrates nada más y nada menos que lograr el acceso a una serie de hechos acerca de Sócrates? Parece difícil, de entrada, imaginar que se trate de cualquier tipo de hechos; e.g., que Sócrates mide tantos y tantos, que tiene los ojos saltones, la nariz achatada, etc. Para llegar a hechos como éstos no parece requerirse el ejercicio de la dialéctica filosófica, cuyo ejercicio está, al menos según la tradición, íntimamente ligado con el mandato del oráculo. Asumamos, entonces, momentáneamente, que Sócrates logra producir una lista con una serie de hechos suficientemente nobles sobre sí mismo. ¿Podría, en ese caso, dar por cumplida la tarea encomendada por el oráculo? ¿Podría Sócrates estar satisfecho, así sea parcialmente, en su búsqueda de autoconocimiento?

Para ilustrar por qué la respuesta debe ser negativa, abordemos la cuestión desde otro ángulo. Supongamos que respuestas satisfactorias a preguntas tales como “¿qué tipo de persona soy?” constituyen ejemplos genuinos de autoconocimiento. Lo que importa en esas interrogantes es 
la persona misma que se las plantea seriamente, el individuo particular que puede describirse como alguien que se conoce a sí mismo en alguna medida y que busca o aspira a conocerse a sí mismo. De ahí que la persona que plantee estas interrogantes no pueda darse por satisfecha con una lista de hechos (no importa cuán sublimes sean) acerca de alguien que podría ser cualquiera sin saber que se trata de ella misma. Podría entonces argüirse que si tomamos el autoconocimiento sólo como el conocimiento de una serie de hechos acerca de uno mismo, perdemos un aspecto importante de la idea de autoconocimiento, tal vez el aspecto más importante y distintivo; a saber, uno mismo.

2. Quiero sugerir, tomando en cuenta las consideraciones anteriores, que nuestra idea de autoconocimiento es una idea tensa, en tanto contiene dos demandas en competencia. Una, que llamo la demanda del desapego, nos pide ser capaces de vernos a nosotros mismos desde cierta distancia; se trata, si se quiere, de estar dispuestos a aceptar las mejores evidencias y a rechazar, ante ellas, incluso nuestras creencias más arraigadas sobre nosotros mismos; estar abierto a los hechos y tomar nuestra propia autobiografía o reportes de sucesos de la misma manera que tomamos los reportes autobiográficos de cualquier persona. Como lo ejemplifican muchos pasajes de la literatura, lo que una persona dice de sí misma puede ser efectivamente una fuente valiosa para saber qué tipo de persona es —de quién estamos hablando—; pero también lo es lo que calla u omite de sí misma. En general, tendemos a tratar de un modo especial, i.e., con algún grado de reserva, los relatos y reportes que las personas hacen de sí mismas, a pesar de que cada persona parece particularmente autorizada para hacerlo. No se trata tan sólo de las reservas que normalmente tenemos ante cualquier reporte de hechos, sino de aquellas que permiten detectar fallas, inconsistencias, titubeos, exageraciones, imprecisiones de quien nos relata un trozo de su vida. ¿Por qué es esto así? En parte, al menos, por la tentación, tan peculiar del narcisismo, de falsear los hechos en su favor. El autoconocimiento requiere desapego, pues exige de la persona ser capaz de reconocer en sí misma esa tentación, o, en términos un tanto menos clericales, ejercer las reservas debidas frente a lo que uno mismo puede decir de sí mismo. Y en este sentido, aceptar la demanda del desapego, que pide a la persona estar abierta a los hechos, es aceptar que hay un hiato, cuando no un abismo, entre lo que una persona cree de sí misma y lo que ella es.

La otra demanda es igualmente importante, y corre en sentido opuesto a la anterior. Propongo llamarla, a falta de un mejor vocablo, la de- 
manda del involucramiento; podría llamarse también de la implicación, siempre que no se tome este término en su acepción lógica, sino en la legal; e.g., en el sentido en que se dice que fulano está implicado en determinados sucesos. Aquí la idea es que la mejor recapitulación de evidencias sobre la vida (corporal, psicológica, emocional, intelectual, moral o financiera) de una persona, incluso si es la persona misma quien la hace, no constituye un ejemplo genuino de autoconocimiento.

Doy ejemplos. Tomo el primero de lo que en la terminología freudiana popularizada se conoce como 'resistencia'. Después de un tiempo de terapia, un sujeto llega a la creencia de que él odia a su padre; no obstante, el sujeto no reconoce tal sentimiento dirigido hacia esa persona en él mismo. Otro ejemplo: representémonos a Edipo en el momento en que no puede resistir la evidencia de que el hombre que él había asesinado en la encrucijada era su padre. Se diría, y es correcto, que ahí Edipo ha adquirido una creencia acerca de sí mismo, y esa creencia es además autoconsciente. Pero es fácilmente imaginable que, aunque reconozca que ha matado a un hombre en la encrucijada, aún no se reconozca a sí mismo como el asesino de su padre, como parricida —en parte por las implicaciones trágicas que eso comporta (diríamos, por su situación personal en el orden del mundo), en parte por ser esa creencia un golpe brutal a su integridad personal-. Estos ejemplos sugieren la observación de que, para conocerse a sí misma, no basta que la persona asuma, en soliloquio o en conversación, determinadas creencias acerca de sí mismo; debe también reconocerse en ellas y estar dispuesta a hacerse cargo de sus consecuencias para el resto de sus creencias y para sus acciones.

Un ejemplo más es el de una persona que relata una serie de hechos acerca de sí misma en algo así como una biografía ideal. Pensemos en las hojas de vida que se elaboran para recibir premios y honores militares o académicos. Los hechos relatados pueden ser todos verídicos; pero cuando la persona se detiene a considerar el relato, ella no se reconoce plenamente en él. ¿Qué está pasando aquí? Independientemente de las explicaciones sicológicas que pudieran darse, hay que observar que, en este caso, la persona efectivamente posee un saber de ciertos hechos sobre sí misma que puede expresar usando el término 'yo'; i.e., algo así como una autobiografía. Por otro lado, no se trata de una falta de realismo, en el sentido de que esta autobiografía oculte cosas como las motivaciones profundas de ciertos logros y empresas, o los medios empleados en el camino. Aun así, pienso que no puede afirmarse que tal autobiografía constituya una forma de autoconocimiento. Al selec- 
cionar un aspecto de su vida, la persona irremediablemente deja fuera muchos otros aspectos, por lo que existe la posibilidad permanente de que, para la persona misma, lo que no se toma en cuenta sea mucho más importante para describir el tipo de persona que es, que lo que ella afirma, incluso verídicamente, en su autobiografía. En esos casos no estamos, como diríamos comúnmente, involucrados personalmente. Por eso, aunque la persona pueda tomar esa autobiografía como un saber de hechos sobre sí misma, no es aún un caso de autoconocimiento. Así, en un segundo sentido, la demanda del involucramiento requiere que los hechos sean suficientemente importantes y suficientemente cercanos para la persona misma, y se plantea en contextos en los que la imparcialidad es especialmente difícil. En suma, lo que la demanda del involucramiento señala es que si sólo contamos con las mejores evidencias sobre los hechos concernientes a nuestra propia persona, podemos ciertamente contar con un conocimiento (cuya calidad depende de la calidad de la evidencia), pero todavía no contamos con autoconocimiento, porque aún no aparece la persona misma que está especialmente involucrada en determinados sucesos y estados de cosas.

Ahora bien, ¿por qué digo que se trata de demandas en conflicto y no, en cambio, de demandas complementarias? Deseo señalar al respecto lo siguiente: en los extremos, favorecer cualquiera de las dos demandas sobre la otra significa perder algo importante de la idea de autoconocimiento. En uno de los extremos, el autoconocimiento deviene en mero sinónimo de saber acerca de hechos y no habría por qué dedicarle atención en la investigación filosófica; y en el de otro, el peligro es convertir el autoconocimiento, cuando se muestra suficientemente articulado, en una narrativa autocomplaciente que se regodea en su propio narcisismo. ${ }^{2}$ Es importante, creo, apreciar que, según el presente planteamiento, de no lograrse alguna forma de equilibrio entre ambas demandas, nuestra idea de autoconocimiento estará seriamente en cuestión —si no como una idea espuria o imposible, sí como una idea con escaso contenido-. Es por ello importante, también, reconocer la tensión que producen ambas demandas, y a lo largo de este ensayo tendremos ocasión de hallarla en otras formas. ${ }^{3}$

\footnotetext{
${ }^{2}$ El desprecio por los hechos es una forma de arrogancia. Cfr. Pereda 1999, pp. 56-57.

${ }^{3}$ Ambas demandas hacen eco de la distinción entre facticidad y libertad en Sartre 1943, pp. 561-637, y entre el espectador y el agente en Moran 2001, pp. 5155, y en el Kant del prólogo a la Antropología en sentido pragmático.
}

Diánoia, vol. LIII, no. 61 (noviembre 2008). 
3. Consideremos una posible objeción a este planteamiento inicial. La tensión mencionada se produce — podría argüirse- sólo si entendemos mal la idea en cuestión, pues el autoconocimiento es, eminentemente, conocimiento interno, o el conocimiento que una persona, acaso, tiene de su propia interioridad. Según esto, los ítems que constituyen el ámbito por excelencia del autoconocimiento son de cierto tipo; a saber, mental o psicológico - las propias creencias, deseos, emociones, etc., de una persona-. Las bondades de un modelo como éste pueden ser variadas. Una de ellas radica en que saca provecho de un aspecto peculiar de la subjetividad humana; es decir, al menos en la mayoría de los casos, en aquellas ocasiones en las que sabemos lo que sentimos o deseamos, creemos, lo hacemos sin necesidad de recabar evidencias; sólo lo sabemos. Este rasgo a veces se ha formulado diciendo que poseemos conocimiento inmediato de nuestros propios estados de conciencia. No es que no pueda considerarse inmediato, por ejemplo, el saber que me encuentro sentado escribiendo sobre una mesa. Después de todo, en muchas ocasiones el saber de nuestras situaciones corporales también es así; no necesitamos evidencias de él. Me percato directamente de que estoy sentado ante una mesa, tal y como percibo sin más ceremonias que la puerta está abierta. Sucede, sin embargo, que este saber puede ser derrotado; esto es, para el modelo en cuestión, mi experiencia de mis propios estados corporales podría ser la misma, aunque mis estados corporales sean de hecho muy diferentes. Típicamente, los filósofos que sostienen un modelo como éste acuden, en su apoyo, a fenómenos tales como el del sueño, a posibilidades meramente teóricas tales como la perversidad de los dioses, los cerebros en cubetas (recibiendo, acaso, información propioceptiva) y a ficciones tales como la de una matriz de experiencias en un mundo creado por las máquinas.

Según este modelo, el conocimiento de nuestro propios estados subjetivos no puede ser derrotado de esa manera, y es por ello que se toma como una especie de estandarte de lo que ha de contar como autoconocimiento. Si me pregunto lo que pienso sobre $p$, y llego a creer que pienso que tal y tal sobre $p$, mi creencia parece estar libre de la posibilidad de error. Aquí, al contrario de lo que pretendidamente sucede con los estados corporales, creer que uno piensa tal y tal implica que uno piensa tal y tal. Lo que uno piensa puede ser, por supuesto, falso, pero no puede ser falso que uno tiene el pensamiento que tiene. Además, desde este punto de vista, si uno se adjudica un pensamiento sobre algo, entonces uno sabe, sin recurrir a evidencias, que uno piensa tal y tal sobre algo. La posibilidad de error parece estar aquí excluida, no 
importa cuán grande resulte ser un posible engaño inducido. Por más que lo que piense pueda llegar a ser falso, si soy capaz de pensar algo en este momento, no puedo ignorar que lo pienso. ${ }^{4}$

Si lo consideramos conveniente, podemos entonces decir que el autoconocimiento es, en efecto, saber hechos acerca de mí mismo, siempre que sean éstos del tipo relevante, esto es, mental o psicológico, y siempre que nuestro acceso a ellos sea inmediato. De modo que no hay tensión alguna en la idea de autoconocimiento. Partiendo de que, en general, cuando sé lo que pienso, lo sé sin evidencias, puedo saber cuáles son los hechos — que pienso tal y tal- y saber también que soy yo, y no cualquier otra persona, quien piensa tal y tal. El conflicto, entonces, entre desapego e involucramiento se convierte en un conflicto aparente que se disuelve en la dialéctica de nuestro acceso a la propia mente.

Es de notarse finalmente, que bajo este modelo podría admitirse la posibilidad del acceso evidencial a la propia mente sin tener que abandonar la noción clave de que el autoconocimiento es fundamentalmente conocimiento interno. Siempre podría argüirse que sólo es posible conocer indirectamente lo que uno piensa, siente o desea, en circunstancias particulares, a condición de que conozca directamente mucho de lo que uno piensa, siente o desea. En otros términos, si es posible lograr el acceso a ésta o aquella creencia, emoción o deseo propios mediante fuentes variadas de evidencia, eso se debe a que hay ya una masa de nuestras creencias, emociones y deseos que conocemos sin evidencia; con ello adquiere entonces pleno sentido la idea de que conocemos nuestra propia mente mejor que cualquier otra cosa - en el sentido más general del término-.

4. Desde una perspectiva óntica, estamos en la mayor proximidad al ente que somos nosotros mismos y que denominamos Dasein; pues somos ese ente mismo. Sin embargo, lo que es ónticamente lo más próximo a nosotros es lo más alejado de nosotros ontológicamente. Descartes titula la segunda de sus meditaciones de metafísica: "De natura mentis humanae: quod ipsa sit notior quam corpus" ("Sobre la índole esencial del espíritu humano que es más cognoscible que la carne y que el cuerpo.") A pesar, o precisamente a causa de esta supuesta superior cognoscibilidad del sujeto, su modo de ser es confundido y pasado por alto, no sólo en Descartes sino en toda su posteridad, de tal forma que ninguna dialéctica del espíritu puede superar el efecto de esta negligencia. (Heidegger 2000, pp. 196-197)

${ }^{4}$ Es ésta una manera de entender uno de los resultados más célebres de la segunda de las Meditaciones metafísicas de Descartes.

Diánoia, vol. LIII, no. 61 (noviembre 2008). 
Traigo a colación este pasaje de Heidegger con el propósito de iluminar la situación filosófica que queremos capturar en nuestra idea de autoconocimiento. En primer lugar, una domesticación de la retórica heideggeriana nos sugiere la idea de que no contamos con una noción adecuada, ya no digamos clara, del fenómeno en cuestión. ${ }^{5}$ De modo que debe intentarse arrojar alguna luz sobre tal idea a partir de su propio carácter problemático. Por ello, en nuestros términos, cualquier intento que resulte en la cancelación de las tensiones internas que caracterizan nuestra idea de autoconocimiento está destinado a distorsionarla. Más aún, el pasaje indica que una distorsión ha ocurrido ya, y que sus efectos sobre lo que pensamos acerca de nosotros mismos son irreversibles. Este último calificativo puede parecer excesivo; recordemos, sin embargo, cuán duro han trabajado los filósofos en contra de esos efectos al considerar tales joyas del escaparate filosófico como son los problemas del mundo externo, de las otras mentes, de la identidad personal, y otros.

La objeción recién considerada (en el parágrafo 3) a nuestro planteamiento inicial representa la distorsión cartesiana que Heidegger y muchos otros ansían evitar y exponer, como el hombre civilizado quiere evitar los mitos. No es fácil, sin embargo, aceptar plenamente las alternativas, como tampoco lo es ver por qué están ellas mismas libres de distorsiones.

Considérese la idea clave de que, normalmente, cuando cada cual sabe lo que piensa, desea, siente, lo hace sin usar, e incluso sin necesitar, evidencias. Esto es lo que cierta tradición moderna llama autoconciencia inmediata de nuestros propios estados mentales. Los casos de autoconciencia inmediata parecen exhibir el peculiar rasgo epistémico de que la mera posesión de la creencia de que uno tiene determinado pensamiento (o de que uno piensa tal y tal sobre tal y tal) es suficiente para justificar esa creencia. Puesto que normalmente sabemos lo que pensamos, deseamos o sentimos sin necesitar evidencias (no importa cuán relevantes y disponibles), nuestros pensamientos, deseos y emociones inmediatamente autoconscientes no parecen estar abiertos a las "debilidades" de aquellos estados o condiciones, psicológicos o de otro tipo, a los que logramos tener acceso recabando evidencia. Es tentador concluir de ahí que la autoconciencia inmediata goza de un grado mayúsculo de aceptabilidad epistémica; no solamente más allá de la duda razonable, sino más allá de toda duda posible; en otros térmi-

${ }^{5}$ Según Heidegger (2000, pp. 213 ss.), ésta es una lección que se extrae de la crítica kantiana de la ilusión racional en los paralogismos de la razón pura. 
nos, que nuestras adscripciones sinceras de lo que pensamos, creemos o deseamos poseen una confiabilidad de la que no gozan las atribuciones de estados psicológicos que puedan hacernos segundas o terceras personas. La certeza, la plena integridad en la justificación, tienen tal vez el atractivo de la redención, especialmente para quienes anhelan cimientos inconmovibles para sus creencias y acciones. Pero esto no tiene por qué ser necesariamente así. Exploremos ahora algunas maneras de resistir esta conclusión.

5. Un camino más o menos obvio es despertar sospechas acerca de lo que llamamos el "rasgo epistémico peculiar" de la autoconciencia inmediata. Algunas observaciones de Wittgenstein pueden leerse de esa manera. ${ }^{6}$ Los conceptos psicológicos, que como cualquier concepto son públicos, se aplican generalmente a las personas sobre la base de evidencias (e.g., comportamiento observable). Es una marca gramatical de tales conceptos el que los usemos en primera persona del presente sin tal base, o sin base alguna; pero no hay ninguna razón para pensar que tales usos gocen de alguna prioridad o deban favorecerse epistémicamente sobre otros. Es cierto que si no podemos dar evidencias en contra de determinada afirmación, tal afirmación no puede ser cuestionada. Pero si tampoco pueden darse evidencias en su favor, ¿por qué prestarle a ella más crédito que a otras afirmaciones? Hacerlo es en realidad tener una mera preferencia impertinente. Es más, ¿por qué debemos suponer que tales nociones epistémicas, como son las de "aceptabilidad", "confiabilidad", "crédito" y "ser mejor conocido que", tienen alguna aplicación en estos casos? En otros términos, si no me puedo equivocar, entonces itampoco puedo estar en lo correcto! ${ }^{7}$ Así que lo que resulta peculiar acerca de los pensamientos, las creencias, los deseos autoconscientes, es que no son epistémicos en absoluto. ${ }^{8}$

Algunos textos de Heidegger ofrecen, tal vez, un rumbo semejante contra el cartesianismo. Para resistir la fórmula expresada en el título de la segunda Meditación, el célebre rector de la Universidad de Heidelberg argumentó que lo que somos, o al menos aquello por lo que nos tomamos, no se caracteriza originariamente por la autoconciencia. A pesar de pertenecer a lo que nos es más próximo y con lo que estamos más familiarizados, la autoconciencia es lo más lejano ontológicamente. Eso explicaría por qué, como insiste, no puede darse una respuesta satisfactoria a las interrogantes sobre el ser - si se quiere,

${ }^{6}$ Davidson 1987, p. 44; Strawson 1959, p. iii.

${ }^{7}$ Véase Wittgenstein 1958, p. 67.

${ }^{8}$ Cfr. Tugendhat 1986, pp. 18 ss.

Diánoia, vol. LIII, no. 61 (noviembre 2008). 
sobre lo que somos y sus vínculos con lo que no somos- si se parte de la autoconciencia individual. La subjetividad autoconsciente sería más bien una función, o un "modo derivado" de una estructura más fundamental; i.e., la del entendimiento. Es parte de la estructura de lo que somos plantear la pregunta por el propio ser, así como interpretarse a sí mismo, ya desde cierto entendimiento de lo que somos. ${ }^{9}$ Por ello, si el entendimiento precede a la autoconciencia, no hay razón para pensar que conocemos nuestros pensamientos, creencias, o deseos mejor que ninguna otra cosa.

Este tipo de consideraciones puede servir, efectivamente, para contrarrestar la seducción del modelo cartesiano. Una vez que la autoconciencia adquiere su lugar en el mundo, ya no parece posible, ni atractivo, interpretarla cartesianamente. ${ }^{10}$ No obstante, hay ciertas zonas de la problemática de la autoconciencia que Heidegger parece dejar intocadas. En particular, no tiene nada que decir acerca de asimetrías, o incluso tensiones, entre distintos modos de acceso a uno mismo; no parece haber nada que ilumine el carácter inmediato de la autoconciencia. Tanto la ruta de la evidencia como la ruta de la autoconciencia inmediata serían rutas que presuponen un mundo de vida articulado, una experiencia vivida (un pasado) y una situación previa de entendimiento; y Heidegger parece sugerir que tales diferencias son pueriles y que vale más abandonarlas.

Una pregunta no menor en este contexto es si acaso el término "entendimiento" caracteriza algo —un ejercicio, un comportamiento, de una persona (de un sujeto finito)—. No está muy claro qué es esta situación estructural de entendimiento que no se identifica con una capacidad humana cuyos ejercicios puedan ser más o menos afortunados, ni con comportamientos públicamente observables. Sartre observó en este marco una dificultad mayúscula en el planteamiento heideggeriano, y arguyó en el sentido de que la autoconciencia no es algo que una persona pueda perder y seguir siendo una persona. "No podemos, primero, suprimir la dimensión 'conciencia' —escribe — ni siquiera para reinstalarla subsecuentemente. Entendimiento sólo tiene sentido si es conciencia del entendimiento." 11

Considérese la siguiente observación:

la idea de un placer inconsciente es completamente absurda. Hay, sin duda, placer débil; puedo ser llevado a experimentar un tenue placer al escuchar

${ }^{9}$ Véase Heidegger 1927/1951; §§ 1-4.

${ }^{10}$ Véase Frank 1997, p. 13.

${ }^{11}$ Sartre 1943, p. 95. 
una melodía suave; éste es un placer que es todo lo que puede ser, dada la conciencia con la que se tiene. Dicho de otro modo, hay conciencia de placeres débiles, o de placeres totales, o de placeres parciales; pero no hay una conciencia parcial de placeres. De ahí que la medida del placer es la conciencia con la que se está teniendo. Por otro lado, el placer no es nada sin la conciencia del placer. No hay un placer previo, que posteriormente asuma la conciencia como una de sus cualidades; pues el placer inconsciente es un absurdo. Tampoco hay conciencia que subsecuentemente adquiera la coloración del placer; pues una conciencia que en sí misma no fuera conciencia de algo sería una conciencia sin sentido. Dicho de otro modo, la conciencia del placer y el placer son una y la misma cosa, o, si se prefiere, el placer tiene a la conciencia como modo particular de ser. ${ }^{12}$

Este pasaje sartreano nos sirve para ilustrar cómo puede entenderse el carácter inmediato de la autoconciencia en términos no epistémicos. Si extendemos la observación sartreana a otros estados psicológicos de un sujeto, manteniendo las diferencias relevantes, arribamos a la idea de que no podemos tener los sentimientos, las creencias y los deseos que tenemos si no somos de hecho conscientes de ellos. No es como si pudiera haber sentimientos, creencias o deseos flotando por allí en la mente de una persona que pudieran ser captados después, por ella misma, como los sentimientos, creencias o deseos que son. No hay creencias ni deseos preexistentes a la conciencia, y no hay conciencia que no sea ya conciencia de algo (psíquico). Se trata de la idea de que el ser (e.g., un placer intenso o una firme creencia) se mide por la conciencia (de un placer intenso, de una firme creencia). A veces Sartre parece referirse a este rasgo de lo psicológico, o de los dados psíquicos [données psychiques], como su ser para sí. Yo creo que esto se podría traducir en términos de la noción de inmediatez antes esbozada; i.e., que normalmente accedemos a nuestros propios estados subjetivos sin recurrir a las evidencias.

Lo que es importante destacar es que, en términos de la descripción sartreana de la autoconciencia, el carácter de inmediatez es "más primordial", más "originario", que lo que la tradición moderna denomina "reflexión". Baste aquí entender la reflexión como una forma de consideración explícita de lo que pensamos, deseamos o sentimos, que involucra una capacidad para preguntarse si se ha de continuar pensando, creyendo, deseando, sintiendo tal y cual. En este aspecto, Sartre se ubica en una tradición que considera prerreflexiva la autoconciencia

${ }^{12}$ J.P. Sartre, "Conscience de soi et connaissance de soi", citado por Frank 1997, p. 5.

Diánoia, vol. LIII, no. 61 (noviembre 2008). 
inmediata y que se remonta a los primeros románticos. ${ }^{13} \mathrm{Si}$ un sentimiento particular (e.g., de placer) o, para el caso, una creencia particular, no es sino la conciencia de ese sentimiento o creencia, parece haber una dimensión de tales dados psíquicos o ítems mentales en el que todavía no están abiertos, por así decirlo, a consideraciones de ningún tipo, una dimensión en la que no pueden plantearse cuestiones sobre si, e.g., un determinado sentimiento de placer (o dolor) ha de continuar o no, sobre si continuar creyendo o deseando tal y cual. ${ }^{14}$ Tales preguntas son inteligibles en el contexto de la estructura "sujeto-objeto", donde las propias creencias, deseos y emociones se vuelven "objetos para la conciencia". Dada esa estructura, es perfectamente lícito hablar de creencias (o emociones, o deseos) de segundo orden que necesitan ser justificadas; o, para el caso, que se justifican de un modo especial. Pero, para Sartre, no hay tal estructura en nuestros estados subjetivos inmediatos. Así que, ante la concepción de que nuestros estados subjetivos autoconscientes gozan de una condición epistémica especial, en cuanto que están justificados por el mero hecho de tenerlos, y de que, por ello, constituyen el autoconocimiento propiamente dicho, se puede replicar, si seguimos las sugerencias de Sartre, que el carácter inmediato de nuestros estados subjetivos significa que de suyo no están sujetos a las consideraciones propias de la reflexión, y, por lo tanto, el mero de hecho encontrarse en un determinado estado subjetivo no representa, para quien lo tiene o se lo adjudica, ninguna ventaja epistémica, ningún acceso privilegiado, en relación con lo que otras personas puedan hacer para adjudicárselo. No hay suficiente distancia, por así decirlo, entre la persona y sus propios estados subjetivos para contar éstos como casos genuinos de autoconocimiento.

Pero, entonces, ¿hay algún sentido en el que el mero tener la creencia de que uno tiene tal y tal pensamiento es suficiente para justificar dicha creencia? Si adoptamos una perspectiva no epistémica como las delineadas recién, se podría contestar: si hay acaso tal sentido, no es el sentido en el que se dice que la autoconciencia es inmediata. Sería tentador en esta situación abandonar por completo la noción de autoconciencia como una puerta falsa hacia la idea de autoconocimiento. Dicho de otro modo, si seguimos concentrados sólo en los pensamientos, deseos, creencias autoconscientes, perderemos las condiciones en las que tiene sentido, por ejemplo, descubrir cosas acerca de uno mis-

${ }^{13}$ Me refiero a la reacción contrailustrada conocida como expresivismo. Véase Frank 1997, pp. 6-7; y también Berlin 2000, p. 199.

${ }^{14}$ Véase e.g., los Sokratische Denkwürdigkeiten de J.G. Hamann, en O'Flaherty 1967. 
mo, y también incluso estar equivocados acerca de esas mismas cosas. Y ahora parece que el único camino abierto en esa dirección es el de las creencias, deseos y emociones que otras personas (segundas y terceras) tienen acerca de nosotros. Así que, lejos de ser inmediato y directo, sólo podríamos tener conocimiento de nosotros mismos a través de los otros. Puesto que nuestra atribución de creencias, deseos y emociones a otros, tanto como la atribución de actitudes, por parte de otros, a nosotros mismos, pueden resultar incorrectas, esta aproximación puede tener la ventaja de la falibilidad y la corregibilidad.

El problema de esta conclusión, como podrá ya anticiparse, es que incluso el mejor reporte basado en las mejores evidencias y testimonios acerca de nosotros mismos nos deja con la posibilidad permanente de que no nos reconozcamos en lo que otros, incluso sinceramente, dicen de nosotros. Si en la situación anterior - centrada en la autoconciencia inmediata - nos rendimos ante la demanda del involucramiento, ahora nos sometemos ante la demanda del desapego. "Yo nunca sé qué creo, si no es por los otros." En ambos casos, sin embargo, nuestra idea de autoconocimiento se desvanece en el aire.

5. Richard Moran nos presenta una alternativa más prometedora al modelo cartesiano de autoconocimiento. Ilustremos el peculiar sesgo que da Moran a la problemática aquí tratada, con una situación familiar en la que otras personas nos informan, tal vez a manera de reproche, acerca de nuestras propias creencias. Imaginemos el siguiente intercambio entre dos personas, Estragón y Vladimir, en el curso de un diálogo:

Estragón : (Irónico) ... tú realmente no crees eso.

Una reacción perfectamente normal de Vladimir sería descalificar a Estragón, como si hablara de algo que cae fuera de su competencia:

Vladimir: (Enfático) Pero tú no puedes creer mis creencias por mí, así que itú no me puedes decir a mí lo que creo!

En esta situación podríamos decir que Vladimir le recuerda a Estragón el tipo de autoridad que cualquier persona tiene sobre sus propias creencias; es única, en cuanto que ninguna otra (segunda o tercera) persona puede asumirla legítimamente; y es intransferible, en cuanto que se trata de una autoridad que ninguna persona puede aspirar a tener sobre las creencias de otros, y que la persona misma, por más que trate, no puede nunca otorgarle a otros sobre sus propias creencias. ¿Qué pasa aquí?

Diánoia, vol. LIII, no. 61 (noviembre 2008). 
Una guía es el principio de transparencia de nuestros pensamientos, según lo propone Moran: para responder al menos a cierto tipo de preguntas acerca de uno mismo echamos mano de los mismos recursos que cuando respondemos a las preguntas acerca del mundo. La idea central es que la pregunta i) ¿Creo que $p$ ? es transparente a la pregunta ii) ¿Es $p$ el caso? - en virtud de que la primera se responde de la misma manera que la segunda-. Ante la pregunta i), no miramos, por decirlo así, hacia nosotros mismos, sino hacia el mundo, hacia lo mismo que miramos cuando contestamos a la pregunta ii). Como lo pone Moran:

Una pregunta en primera persona del presente acerca de una creencia propia se responde haciendo referencia a (o considerando) las mismas razones que justificarían una respuesta a la pregunta correspondiente acerca del mundo. (Moran 2001, p. 62)

En nuestro marco, lo que es crucial del principio de transparencia es que permite explicar la diferencia entre el modo en que una persona se relaciona con sus propias creencias y el modo en que segundas o terceras personas se relacionan con ellas. La transparencia, en otros términos, no es una relación que Estragón pueda sostener con las creencias de Vladimir, y que éste no puede tener con las creencias de Estragón. En cualquier caso, si nos preguntamos por las creencias de otros, hemos de mirar a la persona, a lo que hace, dice, etc.; acudimos a los recursos disponibles para establecer algo así como un hecho psicológico acerca de esa persona. Pero, según el principio de transparencia, ésta no es la relación que guarda normalmente una persona con sus propias creencias. La pregunta “ ¿Creo que $p$ ?”, formulada sinceramente en soliloquio o en coloquio, no es una pregunta acerca de si un determinado hecho psicológico puede adjudicarse a una persona que sucede que soy yo. No es, en esencia, una pregunta que uno responda presentando hechos acerca de uno mismo, sino, en contraste, emprendiendo un proceso de deliberación en torno a las razones para tomar o no tomar el contenido de la creencia como verdadero, y éste es un proceso que generalmente desemboca en la formación de una creencia.

Asumiendo que lo que está en disputa no es la sinceridad de Vladimir, el diferendo entre él y Estragón no podría resolverse emprendiendo una investigación que termine en una descripción verdadera de lo que psicológicamente es el caso en lo que respecta a Vladimir. La disputa sería, más bien, sobre el derecho que tiene Vladimir a una determinada creencia; y es natural que Vladimir reaccione como si Estragón le escatimara ese derecho; pues, desde su punto de vista, su creencia es transparente frente al mundo 
Observemos, no obstante, que hay un peligro - "tanto filosóficamente como para la salud mental de la persona"- en la respuesta de Vladimir. Porque si bien su recordatorio de que nadie puede creer sus creencias en su lugar es perfectamente correcto, no debe de ahí concluir que otros, en este caso Estragón, no están de ninguna manera autorizados a hablar acerca de sus creencias (i.e., las de Vladimir). Y el peligro es, desde luego, deformar la idea de la autoridad de la primera persona. El peligro filosófico es imponer sobre esa idea el vocabulario "demasiadopuramente-epistémico" del acceso especial a la propia vida mental; el peligro psicológico, a su vez, puede describirse como el peligro del narcisismo desbordado. En su respuesta, Vladimir se está privando de una fuente valiosa de conocimiento de sí mismo: la que representan otras personas. Estragón bien podría replicar:

Estragón: Por supuesto que puedo decirte lo que crees. Observo lo que haces, y si realmente creyeras tal y tal, no te comportarías como lo haces.

Vladimir tiene varias posibilidades para responder esta observación. Dos se vislumbran: puede ignorarla y conducirse como si nadie sino él mismo pudiera saber lo que cree; o bien puede disputar la observación presentando descripciones alternativas de la situación, así como otras explicaciones de su conducta. Las razones para adoptar una u otra vía pueden ser múltiples. Si adopta la primera, es probable que la conversación llegue a su fin. Pero si adopta la segunda, y la disputa es sobre descripciones de la situación en cuestión o sobre explicaciones de su conducta, Vladimir ha abandonado la noción de que otras personas no pueden decirle cuáles son sus creencias. Y una vez que ha concedido esto, tiene que reconocer que su autoridad sobre sus propias creencias no es absoluta ni está libre de huecos y fisuras, y que otras personas pueden tener alguna, o tal vez mucha, autoridad sobre su propia vida mental.

Si Vladimir se percata de esto y se pone filosófico, debe darse cuenta de que su autoridad sobre sus propias creencias no puede explicarse aduciendo que él tiene un acceso especial a su propia vida mental, de modo que sus creencias autoconscientes tienen el grado más alto de justificación. Y me parece, además, que está ya psicológicamente preparado para aceptar que, en muchos casos y áreas, otras personas pueden conocerlo mejor de lo que él mismo se conoce.

6. Este diálogo ficticio ilustra los peligros que hay en el camino de satisfacer las prerrogativas de la primera persona sin extenderlas, al mismo 
tiempo, más allá o más acá de lo debido. Visto desde otro ángulo, el peligro de distorsionar la autoridad de la primera persona aparece al considerar las dos maneras de relacionarse uno mismo con la propia vida mental que Moran discute en su libro — viz., las admisiones, y las atribuciones-. Si estamos abiertos a la idea de que algunas otras personas pueden tener autoridad sobre nuestra propia vida mental, tenemos que aceptar, creo, que las atribuciones son una vía no sólo legítima, sino incluso valiosa, hacia el conocimiento de uno mismo. Es bien posible, con mayor o menor seguridad de caso en caso, percatarse de ciertas creencias propias a través de los otros, tanto por sus dichos como por sus acciones. Ahora bien, la autoridad de (algunos) otros para atribuirme, con base en la observación de mi conducta y sin preguntarme nada, determinadas creencias, deseos, sentimientos, etc., tiene su correlato, desde luego, en la autoridad que yo tengo para atribuir, sobre el mismo tipo de bases, creencias, deseos o sentimientos a (algunas) otras personas. En esta situación, ¿qué impide ejercer tal autoridad sobre mi propio caso, y atribuirme creencias o deseos a mí mismo? Si he aceptado la autoridad de otros sobre ciertos asuntos míos (si he aceptado, por ejemplo, hablar de mis creencias, deseos, emociones), he aceptado también que ellos pueden ser una fuente evidencial confiable. Así que, aunque yo no disponga de evidencias, puedo permitirme usar la autoridad de los otros para atribuirme creencias a mí mismo. Dicho de otro modo, es tentador aquí suponer que nuestras creencias autoconscientes son casos en los que, sin evidencias, nos atribuimos a nosotros mismos determinados creencias. ${ }^{15}$

Hay que resistir esta tentación, desde luego. Quien afirmara, bajo el modo de pensar recién delineado, que la autoconciencia es esencialmente autoatribución, desde nuestra perspectiva estaría entregándose completamente a la demanda del desapego. Bien mirada, aquí la ruta eminente hacia nuestra propia vida mental es la de la evidencia. Y si en primera persona del presente nos atribuimos pensamientos o creencias, es porque importamos, de la autoridad de los otros, las bases evidenciales de la atribución. Pero si sólo contamos, directa o indirectamente, con la vía de la evidencia, ¿a qué es a lo que le atribuimos esos pensamientos, creencias, etc.? Además de lindezas tales como los "haces de percepciones" o "sujetos trascendentales", no parece haber nada que podamos reconocer como una persona, ya no digamos como la persona que soy.

${ }^{15}$ Véase Moran 2001, § ss. 3.3. El énfasis de los argumentos de Moran en pasajes clave de su texto radica en mostrar que esta conclusión es incorrecta. 
Por otro lado, puesto que la autoatribución es, a final de cuentas, subsidiaria de la autoridad de los otros, si uno asimila la capacidad de pensar, de creer, de desear, de una persona a su capacidad para atribuirse pensamientos, creencias, etc., siempre puede ser posible que lo que ella se atribuya no coincida con lo que ella de hecho piense, crea, etc. Dicho de otro modo, si sólo contamos con la capacidad de autoatribución de creencias, cabe dudar que alguien como Vladimir pueda legítimamente exclamar: "iTú no puedes creer mis creencias por mí!" Si perdemos nuestra capacidad espontánea para hablar, creer, desear o sentir, en primera persona del presente, si la diluimos en la autoridad de los otros, ¿qué queda de nuestro concepto de persona? ¿Qué queda de nuestra propia vida mental?

Podríamos afirmar que el peligro aquí - filosófico y psicológico- es no sólo distorsionar la autoridad de la primera persona, sino de plano perderla. La autoridad sobre su propia mente es lo que le permite a una criatura que cree y siente tal y tal, ser una persona, y ser precisamente la persona que ella es. Nuestros ancestros ryleanos, incluso si se las ingeniaron para explicar el comportamiento de ciertas criaturas a su alrededor, no eran todavía personas, al menos no personas como nosotros. O, para decirlo de otra manera, en su mundo había "personas", pero no sujetos, no primeras personas; había comportamientos que ellos podían acaso atribuir a ciertas criaturas vivas, pero no había creencias, pensamientos, deseos, al menos no lo que nosotros llamamos tales. En una situación en la que todavía no aparecen sujetos, ¿cómo puede haber autoconocimento?

7. Retomemos ahora, en el contexto de las admisiones, la pregunta de si hay algún sentido en que el mero tener la creencia de que uno tiene un pensamiento sea suficiente para justificarla. En este momento podemos contestar, precavidamente, que sí —eso es lo que normalmente pasa cuando admitimos nuestros pensamientos-. Esto quiere decir que si bien hay casos en los que una persona se puede equivocar acerca de sus pensamientos, creencias etc., esto no impide admitir que las personas generalmente saben lo que piensan y creen, sin recurrir a la autoridad de los otros y sin tener que esperar a que se presenten condiciones para observarse actuar según un patrón de conducta. La posibilidad de equivocarse aquí está siempre latente; es importante reconocerla, porque que abre espacio a la idea de que, en algunas áreas y ocasiones, otras personas pueden conocernos mejor de lo que nosotros mismos nos conocemos; y nos permite, asimismo, evitar tentaciones narcisistas. Más aún, la justificación aquí involucrada no es mejor (ni peor) que 
cualquier otra, pues no se trata de un cumplido epistémico que le damos a nuestra creencia (de que tengo un pensamiento). Por ello, hay que tomar la idea de que, en este contexto y en la mayoría de los casos, la posesión es suficiente para la justificación como una expresión de la autoridad del sujeto sobre sus propios pensamientos y creencias autoconscientes, una autoridad que es también una condición para tener los pensamientos y creencias que otros pueden, eventualmente, atribuir a la misma persona sobre la base de evidencias.

Una vez que las creencias autoconscientes ocupan su lugar como una vía irremplazable hacia nuestra propia vida mental, la autoatribución puede encontrar, a su vez, su sitio como una fuente valiosa para el autoconocimiento, pues es por la ruta de las atribuciones que podemos dar sentido a la idea de que hay muchas "cosas" —incluyendo creencias, emociones y deseos- que ignoramos acerca de nosotros mismos. Y, con ello, creo que podemos vislumbrar cómo podemos alcanzar el difícil equilibrio impuesto sobre nuestra idea de autoconocimiento por las exigencias del involucramiento y del desapego. ${ }^{16}$

\section{BIBLIOGRAFÍA}

Berlin, I., 2000, "Herder y la Ilustración", en H. Hardy (comp.), Vico y Herder, Cátedra, Madrid.

Cassam, Q. (comp.), 1994, Self-Knowledge, Oxford University Press, Oxford. Davidson, D., 1987, "Knowing One's Own Mind", en Cassam 1994, pp. 43-64. DeVries, W.A. y T. Triplett, 2000, Knowledge, Mind and the Given, Hackett, Indianápolis.

Frank, M. 1997, "Subjectivity and Individuality. Survey of a Problem", en D.E. Klemm y G. Zöler (comps.), Figuring the Self. Subject, Absolute, and Others in Classical German Philosophy, SUNY Press, Albany.

Heidegger, M., 1927/1951, Ser y tiempo, trad. José Gaos, Fondo de Cultura Económica, México.

__ 2000, Los problemas fundamentales de la fenomenología, trad. J.J. García Norro, Trotta, Madrid.

Moran, R., 2001, Authority and Estrangement. An Essay on Self-Knowledge, Princeton University Press, Princeton.

${ }^{16}$ Este ensayo se ha beneficiado de las críticas que diversas personas hicieran a versiones previas del mismo. El autor agradece a Talbot Brewer, Guillermo Hurtado, Richard Moran y Pedro Stepanenko por sus comentarios a la primera presentación pública de estas ideas; a Samuel Cabanchik, Eduardo Fermandois y Pablo Quintanilla por sus críticas a la segunda versión del trabajo. Agradecimiento especial merecen Martin Fricke, por sus detallados comentarios escritos, y los dictaminadores anónimos de Diánoia, cuyas observaciones atinadas han sido incorporadas en la versión final. 
O'Flaherthy, J., 1967, Hamann's Socratic Memorabilia, Johns Hopkins University Press, Baltimore.

Pereda, C., 1999, Crítica de la razón arrogante, Taurus, México.

Perry, J., 1994, "The Problem of the Essential Indexical", en Cassam 1994, pp. 167-183.

Ryle, G., 1949, "Self-Knowledge", en The Concept of the Mind, Barnes and Noble, Nueva York.

Sartre, J.-P., 1943, L' Être et le néant, Gallimard, París. [Versión en castellano: El ser y la nada, trad. Juan Valmar, Alianza, Madrid, 1984.

Sellars, W., 1956/1997, Empiricism and the Philosophy of Mind, Harvard University Press, Cambridge, Mass. [Versión en castellano: "El empirismo y la filosofía de lo mental", en Ciencia, percepción y realidad, Tecnos, Madrid, 1971, pp. 139-209.]

Strawson, P.F., 1959, Individuals. An Essay in Descriptive Metaphysics, Methuen, Londres. [Versión en castellano: Individuos. Ensayo de metafísica descriptiva, trad. Alfonso García Suárez y Luis M. Valdés Villanueva, Taurus, Madrid, 1989.]

Tugendhat, E., 1986, Self-Consciousness and Self-Determination, The MIT Press, Cambridge, Mass. [Versión en castellano: Autoconciencia y autodeterminación. Una interpretación lingüístico-analítica, trad. Rosa Helena Santos-Ihlau, Fondo de Cultura Económica, México/Madrid, 1993.]

Wittgenstein, L., 1979, Über Gewissheit/On Certainty, Basil Blackwell, Oxford. [Versión en castellano: Sobre la certeza, trad. Joseph Lluís Prades y Vicent Raga, Gedisa, Barcelona, 1988.]

__ 1958, The Blue and Brown Books, Harper, Nueva York [Versión en castellano: Cuadernos azul y marrón, trad. Francisco Gracia Guillén, Tecnos, Madrid, 1968.]

Recibido el 16 de marzo de 2007; aceptado el 16 de junio de 2008.

Diánoia, vol. LIII, no. 61 (noviembre 2008). 